\title{
Formaldehyde-Induced Contact Dermatitis From an N95 Respirator Mask
}

\author{
Rebecca Candler Clawson, BS; Robert Pariser, MD
}

\section{PRACTICE POINTS}

- Prolonged wearing of N95 respirator masks has been associated with causing or complicating a number of facial inflammatory dermatoses.

- Consider the possibility of contact dermatitis secondary to formaldehyde exposure in individuals wearing N95 masks for prolonged periods.

- Information on the chemical components of N95 masks would be useful for clinicians tasked with evaluating patients with facial inflammatory dermatoses.

\footnotetext{
$T$
} he COVID-19 pandemic has overwhelmed health care facilities and health care providers (HCPs) due to the limited resources available to treat a rapidly expanding patient population. Health care providers have been required to work long hours and put themselves at increased risk of infection by coming into frequent contact with infected patients. In addition to the risk of becoming infected with severe acute respiratory syndrome coronavirus 2, HCPs might be required to wear personal protective equipment (PPE) for the entirety of the workday, which can cause a variety of adverse effects.

During the COVID-19 pandemic, there has been an increase in reported cases of facial acne, pressure injury, urticaria, allergic contact dermatitis (ACD), irritant contact dermatitis (ICD), and exacerbation of underlying cutaneous conditions among health care workers. ${ }^{1-4}$ This increase in dermatologic disorders among HCPs has been associated with the increased utilization of and duration of exposure to PPE-particularly N95 respirator masks and surgical masks. ${ }^{5-7}$ Most studies of these reactions have attributed them to local pressure, friction, hyperhydration, elevated $\mathrm{pH}$, and occlusion caused by prolonged wearing of the masks, resulting ultimately in acne and other rashes ${ }^{8-10}$; however, a few studies have suggested that formaldehyde is a potential culprit underlying the increase in skin reactions to face masks. ${ }^{11-14}$

Formaldehyde is a known skin irritant and has been found to cause ACD and ICD from exposure to textiles and cosmetics treated with this chemical. ${ }^{15-18}$ Both N95 and surgical masks previously have been found to contain sufficient levels of formaldehyde or formaldehydereleasing resins (FRRs) to induce ACD or ICD in susceptible people. ${ }^{12-14}$ In this article, we focus on the role of formaldehyde in N95 masks as a potential cause of ACD and ICD in HCPs who have been wearing PPE during the COVID-19 pandemic.

\section{Formaldehyde: Benefits With Significant Problems}

Formaldehyde is nearly ubiquitous in the textile industry because it confers advantageous properties, including resistance to flames, water, and wrinkling. ${ }^{15}$ Despite these advantages, it has long been established that consumers can become sensitized to formaldehyde and FRRs in textiles after chronic exposure. . $^{15-18}$

A study of Australian HCPs found that 5.2\% of those tested had ACD in response to formaldehyde, which was attributed to their PPE. ${ }^{11}$ In a case report of ACD caused by FRRs, Donovan and Skotnicki-Grant ${ }^{12}$ suggested that 
individuals who are sensitive to formaldehyde are vulnerable to reactions that are exacerbated by friction, warmth, moisture, and tight-fitting materials-all of which can occur when wearing an N95 mask. In that report, a formaldehyde-sensitive patient had a strong positive reaction on patch testing to melamine formaldehyde and to a piece of her N95 mask while taking prednisone $8 \mathrm{mg} / \mathrm{d}$, suggesting that some sensitized patients have a strong reaction to their mask even when they are immunosuppressed. ${ }^{12}$

This finding, along with the known formaldehyde content of some N95 masks, suggests that these masks might be a cause of contact dermatitis in some HCPs. Somewhat complicating the situation is that falsenegative patch testing can occur in and might contribute to the underdiagnosis of formaldehyde-induced N95 mask facial dermatitis. ${ }^{12,13}$ Some HCPs have reported mild respiratory symptoms and eye irritation associated with the use of an N95 mask-symptoms that are consistent with formaldehyde exposure. In some cases, those symptoms have caused discomfort sufficient to prompt HCPs to take leave from work. ${ }^{13,14}$

Development of contact dermatitis in response to an N95 mask is not novel; this problem also was observed during the severe acute respiratory syndrome pandemic of the early 2000s. ${ }^{9,17}$ Some HCPs noticed onset of skin reactions after they were required to wear an N95 mask in the workplace, which some studies attributed to material in the mask increasing the likelihood of developing an adverse reaction. ${ }^{2,6,8}$ The components of N95 masks and the materials from which they are manufactured are listed in the Table. ${ }^{19}$

\section{Material Content of the Components of an N95 Respirator Mask ${ }^{19}$}

\begin{tabular}{ll}
\hline Component & Material \\
\hline Strap & Polyisoprene \\
\hline Staple & Steel \\
\hline Nose foam & Polyurethane ${ }^{a}$ \\
\hline Nose clip & Aluminum \\
\hline Filter & Polypropylene ${ }^{b}$ \\
\hline Valve & Polypropylene ${ }^{b}$ \\
\hline Valve diaphragm & Polyisoprene \\
\hline Shell & Polyester $^{b}$ \\
\hline
\end{tabular}

This material might contain added formaldehyde or formaldehyde-releasing resins, depending on the manufacturer.

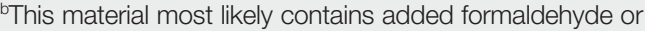
formaldehyde-releasing resins.
Other studies have shown that formaldehydesensitive individuals had positive patch test reactions to the fabric of N95 and surgical masks, which was found to contain free formaldehyde or FRRs. ${ }^{12-14}$ However, there are limited reports in the literature confirming the presence of formaldehyde in N95 masks, suggesting the need for (1) more patch testing of N95 mask fabric and (2) correlative high-performance liquid chromatography analysis of the masks to confirm that formaldehydesensitive individuals are at risk of formaldehyde-related dermatosis in response to an N95 mask. The absence of any regulatory requirements to list the chemical components of N95 masks makes it impossible for mask users to avoid exposure to potential irritants or carcinogens.

\section{Face Masks, Adverse Reactions, and Formaldehyde}

Allergic contact dermatitis and ICD typically are rare responses to wearing facial masks, but the recent COVID-19 pandemic has forced HCPs to wear masks for longer than 6 hours at a time and to reuse a single mask, which has been shown to increase the likelihood of adverse reactions..$^{1,4,6}$ Additionally, humid environments, tight-fitting materials, and skin abrasionsall of which can be induced by wearing an N95 mask-have been found to increase the likelihood of formaldehyde-related contact dermatitis by increasing the release of free formaldehyde or by enhancing its penetration into the skin..$^{6,20,21}$

Formaldehyde is an ubiquitous chemical agent that is part of indoor and outdoor working and residential environments. Health care professionals have many opportunities to be exposed to formaldehyde, which is a well-known mucous membrane irritant and a primary skin-sensitizing agent associated with both contact dermatitis (type IV hypersensitivity reaction), and an immediate anaphylactic reaction (type I hypersensitivity reaction). ${ }^{22-25}$ Exposure to formaldehyde by inhalation has been identified as a potential cause of asthma. ${ }^{26,27}$ More studies on the prevalence of formaldehyde-induced hypersensitivity reactions would be beneficial to HCPs for early diagnosis of hypersensitivity, adequate prophylaxis, and occupational risk assessment.

N95 mask dermatitis also heightens the potential for breaches of PPE protocols. The discomfort that HCPs experience in response to adverse skin reactions to masks can cause an increased rate of inappropriate maskwearing, face-touching during mask adjustment, and removal of the mask in the health care setting. ${ }^{28}$ These acts of face-touching and PPE adjustment have been shown to increase microbial transmission and to reduce the efficacy of PPE in blocking pathogens. ${ }^{29,30}$

Considering the mounting evidence that widespread use of masks effectively prevents viral transmission, it is crucial that all HCPs wear appropriate PPE when treating patients during the COVID-19 pandemic. ${ }^{31,32}$ The recent surge in $\mathrm{ACD}$ and ICD among HCPs in response 
to wearing N95 masks creates a need to determine the underlying cause of these dermatoses and find methods of mitigating sensitization of HCPs to the offending agents. The current epidemiology of COVID-19 in the United States suggests that PPE will be necessary for much longer than originally anticipated and will continue to be worn for long hours by HCPs.

\section{Formaldehyde-Free Alternatives?}

Some researchers have proposed that using materials that are free of allergens like formaldehyde might be a long-term solution to the development of contact dermatitis. ${ }^{15,33}$ Formaldehyde is used in the finishing process of N95 masks for wrinkle and crease resistance and to prevent mildew. It is possible that formaldehyde could be completely removed from the manufacturing process, although no studies on the effects of such alternatives on mask efficacy have been performed.

Formaldehyde-free alternatives that would confer similar properties on textiles have been explored; the most promising alternative to formaldehyde in crosslinking cellulose fibers is polycarboxylic acid in combination with sodium hypophosphite, which can help avoid the adverse health outcomes and environmental impact of formaldehyde. ${ }^{34-36}$ Studies of such alternatives in the manufacturing of N95 masks would be needed to establish the efficacy and durability of formaldehyde-free PPE.

\section{Final Thoughts}

Additional studies are needed to confirm the presence of formaldehyde in N95 masks and to confirm that the mask material yields a positive patch test in sensitized individuals. The paucity of available studies that quantify formaldehyde or FRR content of N95 and surgical masks makes it difficult to establish an association between the chemical content of masks and the prevalence of mask dermatitis among HCPs; however, available reports of skin reactions, including contact dermatitis, from PPE suggest that formaldehyde sensitivity might be at least part of the problem. As such, we propose that manufacturers of $\mathrm{N} 95$ and surgical masks be required to reveal the chemical components of their products so that consumers can make educated purchasing decisions.

\section{REFERENCES}

1. Lan J, Song Z, Miao X, et al. Skin damage among health care workers managing coronavirus disease-2019. letter. J Am Acad Dermatol. 2020;82:1215-1216. doi:10.1016/j.jaad.2020.03.014

2. Yan $Y$, Chen $\mathrm{H}$, Chen L, et al. Consensus of Chinese experts on protection of skin and mucous membrane barrier for health-care workers fighting against coronavirus disease 2019. Dermatol Ther. 2020;33:e13310. doi:10.1111/dth.13310

3. Elston DM. Occupational skin disease among health care workers during the coronavirus (COVID-19) epidemic. J Am Acad Dermatol. 2020;82:1085-1086. doi:10.1016/j.jaad.2020.03.012

4. Balato A, Ayala F, Bruze M, et al. European Task Force on Contact Dermatitis statement on coronavirus disease-19 (COVID-19) outbreak and the risk of adverse cutaneous reactions. J Eur Acad Dermatol Venereol. 2020;34:E353-E354. doi:10.1111/jdv.16557
5. Hu K, Fan J, Li X, et al. The adverse skin reactions of health care workers using personal protective equipment for COVID-19. Medicine (Baltimore). 2020;99:e20603. doi:10.1097/MD.0000000000020603

6. Singh M, Pawar M, Bothra A, et al. Personal protective equipment induced facial dermatoses in healthcare workers managing coronavirus disease 2019. J Eur Acad Dermatol Venereol. 2020;34:E378-E380. doi:10.1111/jdv.16628

7. Zhou P, Huang Z, Xiao Y, et al. Protecting Chinese healthcare workers while combating the 2019 novel coronavirus. Infect Control Hosp Epidemiol. 2020;41:745-746. doi:10.1017/ice.2020.60

8. Hua W, Zuo Y, Wan R, et al. Short-term skin reactions following use of N95 respirators and medical masks. Contact Dermatitis. 2020; 83:115-121. doi:10.1111/cod.13601

9. Foo CCI, Goon ATJ, Leow Y-H, et al. Adverse skin reactions to personal protective equipment against severe acute respiratory syndrome-a descriptive study in Singapore. Contact Dermatitis. 2006;55:291-294. doi:10.1111/j.1600-0536.2006.00953.x

10. Zuo Y, Hua W, Luo Y, et al. Skin reactions of N95 masks and medial masks among health-care personnel: a self-report questionnaire survey in China. Contact Dermatitis. 2020;83:145-147. doi:10.1111/cod.13555

11. Higgins CL, Palmer AM, Cahill JL, et al. Occupational skin disease among Australian healthcare workers: a retrospective analysis from an occupational dermatology clinic, 1993-2014. Contact Dermatitis. 2016;75:213-222. doi:10.1111/cod.12616

12. Donovan J, Skotnicki-Grant S. Allergic contact dermatitis from formaldehyde textile resins in surgical uniforms and nonwoven textile masks. Dermatitis, 2007;18:40-44. doi:10.2310/6620.2007.05003

13. Donovan J, Kudla I, Holness LD, et al. Skin reactions following use of N95 facial masks. meeting abstract. Dermatitis. 2007;18:104.

14. Aerts O, Dendooven E, Foubert K, et al. Surgical mask dermatitis caused by formaldehyde (releasers) during the COVID-19 pandemic. Contact Dermatitis. 2020;83:172-1173. doi:10.1111/cod.13626

15. Fowler JF. Formaldehyde as a textile allergen. Curr Probl Dermatol. 2003;31:156-165. doi:10.1159/000072245

16. Schorr WF, Keran E, Plotka E. Formaldehyde allergy: the quantitative analysis of American clothing for free formaldehyde and its relevance in clinical practice. Arch Dermatol. 1974;110:73-76. doi:10.1001/archderm.1974.01630070041007

17. Slodownik D, Williams J, Tate B, et al. Textile allergy-the Melbourne experience. Contact Dermatitis. 2011;65:38-42. doi:10.1111 /j.1600-0536.2010.01861.x

18. O'Quinn SE, Kennedy CB. Contact dermatitis due to formaldehyde in clothing textiles. JAMA. 1965;194:593-596. doi:10.1001/jama.1965.03090190015003

19. Technical specification sheet-3M $3 \mathrm{M}^{\mathrm{TM}}$ Particulate Respirator 8210, N95. Published 2018. 3M website. Accessed July 12, 2021. https://multimedia.3m.com/mws/media/1425070O/3m-particulate -respirator-8210-n95-technical-specifications.pdf

20. Bhoyrul B, Lecamwasam K, Wilkinson M, et al. A review of nonglove personal protective equipment-related occupational dermatoses reported to EPIDERM between 1993 and 2013. Contact Dermatitis. 2019;80:217-221. doi: 10.1111/cod.13177

21. Lyapina M, Kissselova-Yaneva A, Krasteva A, et al. Allergic contact dermatitis from formaldehyde exposure. Journal of IMAB - Annual Proceeding (Scientific Papers). 2012;18:255-262. doi:10.5272/jimab.2012184.255

22. Foussereau J, Cavelier C, Selig D. Occupational eczema from para-tertiary-butylphenol formaldehyde resins: a review of the sensitizing resins. Contact Dermatitis. 1976;2:254-258. doi:10.1111/j.1600-0536.1976.tb03043.x

23. Frølich KW, Andersen LM, Knutsen A, et al. Phenoxyethanol as a nontoxic substitute for formaldehyde in long-term preservation of human anatomical specimens for dissection and demonstration purposes. Anat Rec. 1984;208:271-278. doi:10.1002/ar.1092080214

24. Bolt HM. Experimental toxicology of formaldehyde. J Cancer Res Clin Oncol. 1987;113:305-309. doi:10.1007/BF00397713

25. Arts JHE, Rennen MAJ, de Heer C. Inhaled formaldehyde: evaluation of sensory irritation in relation to carcinogenicity. Regul Toxicol Pharmacol. 2006;44:144-160. doi:10.1016/j.yrtph.2005.11.006 
26. Kim CW, Song JS, Ahn YS, et al. Occupational asthma due to formaldehyde. Yonsei Med J. 2001;42:440-445. doi:10.3349/ymj.2001.42.4.440

27. Nordman H, Keskinen H, Tuppurainen M. Formaldehyde asthmarare or overlooked? J Allergy Clin Immunol. 1985;75(1 pt 1):91-99. doi:10.1016/0091-6749(85)90018-1

28. Kantor J. Behavioral considerations and impact on personal protective equipment use: early lessons from the coronavirus (COVID-19) pandemic. J Am Acad Dermatol. 2020;82:1087-1088. doi:10.1016/j. jaad.2020.03.013

29. KwokYLA, Gralton J, McLaws M-L. Face touching: a frequent habit that has implications for hand hygiene. Am J Infect Control. 2015;43:112-114. doi:10.1016/j.ajic.2014.10.015

30. Nicas M, Best D. A study quantifying the hand-to-face contact rate and its potential application to predicting respiratory tract infection. J Occup Environ Hyg. 2008;5:347-352. doi:10.1080/15459620802003896

31. MacIntyre CR, Chughtai AA. A rapid systematic review of the efficacy of face masks and respirators against coronaviruses and other respiratory transmissible viruses for the community, healthcare workers and sick patients. Int J Nurs Stud. 2020;108:103629. doi:10.1016/j.ijnurstu.2020.103629

32. Garcia Godoy LR, Jones AE, Anderson TN, et al. Facial protection for healthcare workers during pandemics: a scoping review. BMJ Glob Health. 2020;5:e002553. doi:10.1136/bmjgh-2020-002553

33. Svedman C, Engfeldt M, Malinauskiene L. Textile contact dermatitis: how fabrics can induce ermatitis. Curr Treat Options Allergy. 2019;6:103-111. doi:10.1007/s40521-019-0197-5

34. Yang CQ, Wang X, Kang I-S. Ester crosslinking of cotton fabric by polymeric carboxylic acids and citric acid. Textile Res J. 1997;67:334-342. https://doi.org/10.1177/004051759706700505

35. Welch CM. Formaldehyde-free durable-press finishes. Rev Prog Coloration Related Top. 1992;22:32-41. https://doi .org/10.1111/j.1478-4408.1992.tb00087.x

36. Peng H, Yang CQ, Wang S. Nonformaldehyde durable press finishing of cotton fabrics using the combination of maleic acid and sodium hypophosphite. Carbohydrate Polymers. 2012;87:491-499. doi:10.1016/j.carbpol.2011.08.013 